ARTICLE

https://doi.org/10.1038/s41467-019-10315-9

\title{
Switching acidity on manganese oxide catalyst with acetylacetones for selectivity-tunable amines oxidation
}

Xiuquan Jia (1) ${ }^{1}$, Jiping $M a^{1}$, Fei Xia ${ }^{1,2}$, Mingxia Gao ${ }^{1,2}$, Jin Gao ${ }^{1} \&$ Jie Xu (1) ${ }^{1}$

The design of metal oxide catalysts predominantly focuses on the composition or geometry engineering to enable optimized reactivity on the surface. Despite the numerous reports investigating the surface chemisorption of organic molecules on metal oxides, insights into how adsorption of organic modifiers can be exploited to optimize the catalytic properties of metal oxides are lacking. Herein, we describe the use of enolic acetylacetones to modify the surface Lewis acid properties of manganese oxide catalysts. The acetylacetone modification is stable under the reaction conditions and strongly influences the redox-acid cooperative catalysis of manganese oxides. This enables a rational control of the oxidation selectivity of structurally diverse arylmethyl amines to become switchable from nitriles to imines.

\footnotetext{
${ }^{1}$ State Key Laboratory of Catalysis, Dalian National Laboratory for Clean Energy, Dalian Institute of Chemical Physics, Chinese Academy of Sciences, Dalian 116023, China. ${ }^{2}$ University of Chinese Academy of Sciences, Beijing 100049, China. Correspondence and requests for materials should be addressed to J.M. (email: majiping@dicp.ac.cn) or to J.X. (email: xujie@dicp.ac.cn)
} 
Es: nhanced control of selectivity has been a key focus in catalysis science ${ }^{1-7}$. In the past few years, the excitement that surrounds the discovery of selectivity-tunable chemical processes was stoked by the heterogeneous catalysts with precisely controllable reactivities ${ }^{8-14}$. Still, repetitive and exhausting engineering of the composition or geometry of catalysts is frequently required to switch selectivity in the case of the consecutive reaction generating more than one compound of importance. Apart from alteration of the intrinsic characteristics of catalysts, surface modification provides a facile way to switching selectivity to different products over the same catalyst by controlling the reactant orientation or availability of specific sites on the catalyst surface $4,8,15,16$. Owing to the fascinating flexibility of organic modifiers, organic modification has evolved into very powerful and effective technique for the selectivity control of supported metal catalysts $2,4,8,17-21$. Much less is known about the study on tuning the selectivity of metal oxide catalyst via organic modification ${ }^{22,23}$, although metal oxides are used in various fields of bifunctional catalysis as a result of their acid-base and redox properties with high thermal stability and durability ${ }^{24-28}$.

Organic adsorbates on metal oxides were extensively probed for insights into the mechanistic chemistry. By contrast, how the organic adsorbate-metal-oxide interaction can be exploited to optimize the catalytic properties of metal oxides remains unclear, which would be more attractive from the viewpoint of practical chemistry. In this study, the selective oxidation of primary amines was chosen as the model consecutive reaction for studies on the effect of organic modification on the selectivity switch of metal oxide catalysts. The dual functions of both Lewis acid and redox properties make manganese oxides $\left(\mathrm{MnO}_{\mathrm{x}}\right)$ a promising catalyst for the aerobic oxidation of amines to obtain imines, nitriles or amides via oxidative dehydrogenation and successive hydrolysis ${ }^{29-31}$. On the other hand, the selective synthesis of imines or nitriles via this bifunctional catalysis process is still challenging. A general feature of such reactions is the reversible and uncontrollable hydrolysis of the $\mathrm{C}=\mathrm{N}$ bond in aldimine intermediates or imines promoted by the Lewis acidity of $\mathrm{MnO}_{\mathrm{x}}{ }^{29,30,32}$. Developing ways to control the cooperations between the redox and acid properties on $\mathrm{MnO}_{\mathrm{x}}$ catalysts is therefore worthwhile.

We have now made such catalysts by employing amorphous $\mathrm{MnO}_{\mathrm{x}}$ as redox-acid cooperative catalyst for the double dehydrogenation of primary amines to nitriles, and the acetylacetone (acac) modifier switches the selectivity from nitriles to imines by selectively suppressing the Lewis acidic sites on $\mathrm{MnO}_{\mathrm{x}}$ catalyst. This work provides an opportunity for using manganese oxide catalyst for the synthesis of both imines and nitriles in high selectivity from primary amines via aerobic oxidation, and contributes an example of regulating the catalytic selectivity of metal oxide catalysts by organic modification on the surface.

\section{Results}

Aerobic oxidation of primary amines over manganese oxides. The aerobic oxidation of benzylamine was selected as a model reaction. As shown in Table 1, using well-crystallized $\mathrm{MnO}_{2}$ catalysts, a near quantitative conversions were observed, and the yields of nitrile (3a) varied from $24.6 \%$ to $58.9 \%$, with $24.1-61.9 \%$ yield of imine (2a) formed (Table 1, entries 1-4). In comparison, amorphous $\mathrm{MnO}_{\mathrm{x}}$ has much increased specific surface area and mass-specific activity (Supplementary Table 1$)^{23}$, affording a complete conversion of amine and $86.5 \%$ yield of nitrile (3a) (Table 1, entry 5). The time course of the synthesis of $\mathbf{3 a}$ over amorphous $\mathrm{MnO}_{\mathrm{x}}$ displays a steep volcano curves for $\mathbf{2 a}$, indicating that the imine of $\mathbf{2 a}$ is the reaction intermediate and could be hardly obtained in high selectivity via tuning of the reaction time (Supplementary Fig. 1). Benzamide was detected as the main byproduct (Supplementary Fig. 7). Accordingly, the double dehydrogenation reaction of the primary amines to nitriles was more favorable in the case of using amorphous $\mathrm{MnO}_{\mathrm{x}}$ catalyst in comparison with the studied crystallized $\mathrm{MnO}_{2}$. Next, we explored the possibility of enhancing the selectivity for $\mathbf{2 a}$ over $\mathrm{MnO}_{\mathrm{x}}$ catalyst. By reducing the reaction temperature or ratio of the catalyst to the substrate, $\sim 46.7 \%$ yield of $2 \mathbf{a}$ was obtained as the highest yield (Fig. 1, entries 6-7). Notably, when the $\mathrm{MnO}_{\mathrm{x}}$ catalyst was modified with acac by immersing the catalyst in an acetonitrile solution of acac and stirring at $90^{\circ} \mathrm{C}$ for $4 \mathrm{~h}$, the second dehydrogenation step of imine oxidation was prohibited, and a dramatic change in selectivity from nitrile toward imine product was observed (Table 1, entry 8; Supplementary Figs. 1 and 8). However, the mass-specific activity was decreased after modification. Thus, the switched selectivity was not because of an increase in the rate of the desired reaction but rather a result of inhibition of the undesired reaction for the modified catalyst.

Acac and its derivatives are particularly attractive in the functionalization of metal oxide nanoparticles for its capability to form stable adsorption on metal oxide surfaces ${ }^{33-35}$. As shown in Fig. 1, the $\mathrm{MnO}_{\mathrm{x}}$ modified by 2-acetylcyclohexanone (2), 3-butyl-2,4-pentanedione (3) or 3-methyl-2,4-pentanedione (4) produced imine with a similar yield of $\sim 90 \%$. These results suggest that the acac derivatives with different substituent groups are effective modifiers for tuning the selectivity. Modification with pyridine (6) just provided a slight increase in the yield of imine relative to that of clean $\mathrm{MnO}_{\mathrm{x}}$. And moderate yield of imine was observed upon increasing the amount of pyridine by 10 times. By contrast, 8-hydroxyquinoline (5) gave an obvious increase in the yield of imine, possibly due to the higher stability of bidentate coordination in comparison with the monodentate pyridine modifiers. Moreover, surface coverages of $5-6 \mu \mathrm{mol} \mathrm{m}{ }^{-2}$ were observed for the modifiers of acac (1), 2-acetylcyclohexanone (2), 3-butyl-2,4-pentanedione (3), 3-methyl-2,4-pentanedione (4), and 8-hydroxyquinoline (5) (Supplementary Figs. 2 and 3). By contrast, a considerably low surface coverage was observed over pyridine (6) (Supplementary Fig. 2). This is in accordance with the performance of $\mathrm{MnO}_{\mathrm{x}}$ modified by these modifiers in the aerobic oxidation of benzylamine. For $\beta$-dicarbonyl compounds, a keto-enol tautomerism usually exists ${ }^{36-38}$. And the reaction pathways over the $\mathrm{MnO}_{\mathrm{x}}$ catalyst might be directed by the keto form or enolic form of acac. 3,3-Dimethyl-2,4-pentanedione (7), lacking the proton required to generate the enol form of $\beta$-diketones ${ }^{39}$, minimally affected the selectivity relative to that of clean $\mathrm{MnO}_{\mathrm{x}}$, which differs especially from the other acac derivatives. In addition, the surface coverage of 3,3-dimethyl-2,4pentanedione (7) is the lowest among the tested modifiers (Supplementary Figs. 2 and 4). Thus, we deduce that, during the self-assembly process, the enolic form of acac rather than the keto is the indispensable species for regulating the surface properties of $\mathrm{MnO}_{\mathrm{x}}$ which gets the catalytic selectivity to switch from nitrile to imine.

Effect of acac modification on surface properties of $\mathrm{MnO}_{\mathrm{x}}$. Next, the mode of acac adsorption as well as the resulting surface regulation effect on $\mathrm{MnO}_{\mathrm{x}}$ was studied. The self-assembly of acac on the surfaces of $\mathrm{MnO}_{\mathrm{x}}$ was characterized by Fourier transform infrared (FT-IR) spectroscopy (Fig. 2a). In order to probe whether coordination interaction occurred between acac and the $\mathrm{MnO}_{\mathrm{x}}$ surface, we have compared the IR spectroscopy of free acac and acac modified $\mathrm{MnO}_{\mathrm{x}}$. For free acac, two $\mathrm{C}=\mathrm{O}$ stretching bands at 1728 and $1709 \mathrm{~cm}^{-1}$, one $\mathrm{C}=\mathrm{C}$ stretching band at $1625 \mathrm{~cm}^{-1}$ and two $\mathrm{CH}_{3}$ bending vibration bands at 1421 and $1360 \mathrm{~cm}^{-1}$ were observed, all of which are attributed to enolic acac with varied 


\section{Table 1 The catalytic performance of manganese oxide catalysts in the benzylamine aerobic oxidation reaction}

\begin{tabular}{|c|c|c|c|c|c|}
\hline \multirow[t]{2}{*}{ Entry } & \multirow[t]{2}{*}{ Cat. } & \multirow[t]{2}{*}{ Mass-specific activity $\left(\mathrm{mmol} \mathrm{g}_{\mathrm{cat}}{ }^{-1} \mathrm{~h}^{-1}\right)$} & \multirow[t]{2}{*}{ Conv. (\%) } & \multicolumn{2}{|l|}{ Yield (\%) } \\
\hline & & & & $2 a$ & $3 a$ \\
\hline 1 & $\alpha-\mathrm{MnO}_{2}$ & $45.4 \pm 2.1$ & $94.5 \pm 0.4$ & $47.9 \pm 2.4$ & $44.6 \pm 3.1$ \\
\hline 2 & $\gamma-\mathrm{MnO}_{2}$ & $61.8 \pm 4.0$ & $97.4 \pm 0.2$ & $58.6 \pm 4.4$ & $32.5 \pm 3.7$ \\
\hline 5 & $\mathrm{MnO}_{\mathrm{x}}$ & $129.2 \pm 4.2$ & $>99$ & 0 & $86.5 \pm 0.3$ \\
\hline $6^{a}$ & $\mathrm{MnO}_{\mathrm{x}}$ & - & $>99$ & $7.0 \pm 1.2$ & $80.1 \pm 1.0$ \\
\hline $7^{a}, b$ & $\mathrm{MnO}_{\mathrm{x}}$ & - & $93.0 \pm 0.2$ & $46.7 \pm 0.2$ & $41.2 \pm 2.5$ \\
\hline 8 & acac- $\mathrm{MnO}_{\mathrm{x}}$ & $14.7 \pm 1.9$ & $94.1 \pm 0.3$ & $90.6 \pm 4.1$ & $3.4 \pm 0.2$ \\
\hline
\end{tabular}

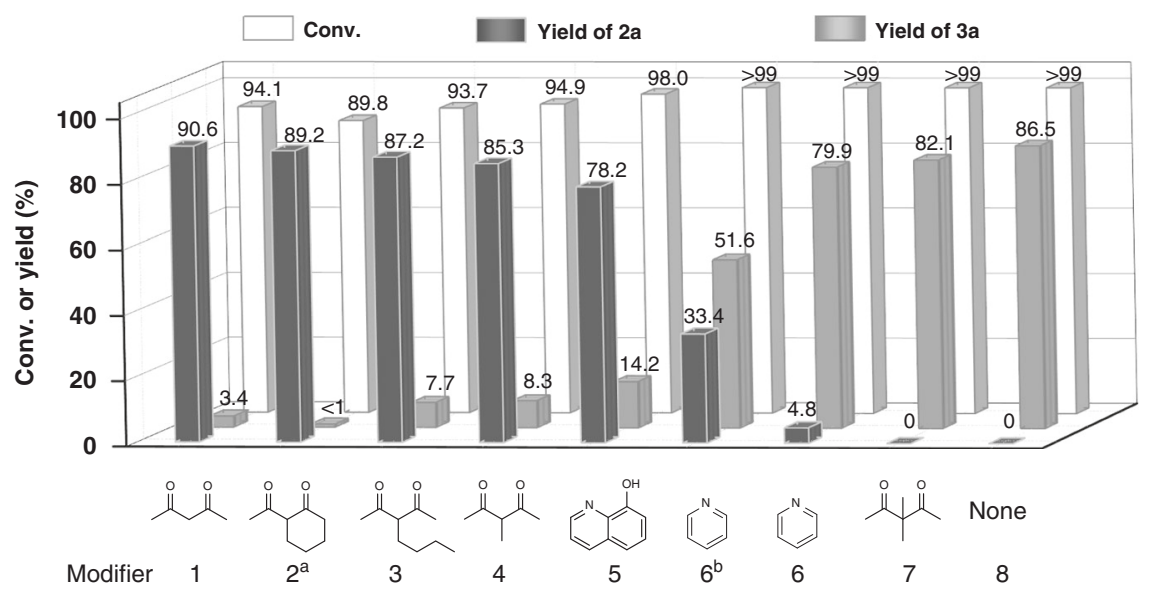

Fig. 1 Performance of $\mathrm{MnO}_{x}$ with different modifiers in the aerobic oxidation of benzylamine. Reaction conditions: $1 \mathrm{mmol}$ benzylamine, $0.1 \mathrm{mmol} \mathrm{MnO}_{\mathrm{x}}$ additive $/ \mathrm{MnO}_{\mathrm{x}}=20 \mathrm{~mol} \%, 5 \mathrm{~mL} \mathrm{CH}{ }_{3} \mathrm{CN}, 0.3 \mathrm{MPa} \mathrm{O}_{2}, 90^{\circ} \mathrm{C}, 14$ h. ${ }^{a} 20$ h. b Additive $/ \mathrm{MnO}_{\mathrm{x}}=200 \mathrm{~mol} \%$

conformations ${ }^{40}$. After the acac deposition on $\mathrm{MnO}_{\mathrm{x}}$, the $\mathrm{C}=\mathrm{O}$ stretching bands attributed to free acac disappeared, and two bands were observed at 1556 and $1342 \mathrm{~cm}^{-1}$ that arise from the metalcomplexed $\mathrm{CO} / \mathrm{CC}$ stretching and $\mathrm{CH}_{3}$ symmetrical bending vibration of coordinated acac, respectively ${ }^{41,42}$. This indicates the formation of bidentate ligand from the enol form of acac via losing its proton and subsequent coordination on the surface of $\mathrm{MnO}_{\mathrm{x}}$. The retainment of the vibration peaks after evacuation at $150{ }^{\circ} \mathrm{C}$ for $0.5 \mathrm{~h}$ established the stability of acac modification.

To examine the effect of acac modification on the surface properties of $\mathrm{MnO}_{\mathrm{x}}$, in situ FT-IR spectroscopic characterization of pyridine adsorption was performed (Fig. 2b). The significant band at $1440 \mathrm{~cm}^{-1}$ was observed in the spectrum of unmodified $\mathrm{MnO}_{\mathrm{X}}$, assigned to coordinatively bound pyridine on Lewis acidic sites, indicating that the unmodified $\mathrm{MnO}_{\mathrm{x}}$ surface is covered by Lewis acidic sites ${ }^{27,43}$. By contrast, after pre-adsorption of acac on $\mathrm{MnO}_{\mathrm{x}}$, the band at $1440 \mathrm{~cm}^{-1}$ was scarcely observed under identical conditions. These results demonstrate that the Lewis acidic sites on the surface of $\mathrm{MnO}_{\mathrm{x}}$ can be blocked by preadsorption of acac modifier.

It is reasonable to expect the retention of Lewis acidity in those modified catalysts which showed low selectivity for imine. As shown in Supplementary Fig. 5, in situ FT-IR spectroscopic characterization of pyridine adsorption confirmed the preservation of Lewis acidity on 3,3-dimethyl-2,4-pentanedione (7) modified $\mathrm{MnO}_{\mathrm{x}}$, which gave nitrile as the primary product in the aerobic oxidation of benzylamine (Fig. 1). To examine the acid property of catalysts showing intermediate selectivity, $\mathrm{MnO}_{\mathrm{x}}$ modified with a decreased amount of $10 \mathrm{~mol} \%$ acac was prepared and tested. A residual Lewis acidity was observed for $10 \mathrm{~mol} \%$ acac modified $\mathrm{MnO}_{\mathrm{x}}$ (Supplementary Fig. 5), which afforded a medium yield $(51.0 \%)$ of imine (2a) under identical conditions (Supplementary Fig. 6).

Understanding the switchable selectivity over $\mathrm{MnO}_{\mathrm{x}}$ catalyst. If the availability of Lewis acid sites on a metal oxide surface can be controlled, the reaction promoted by the acidity of the catalyst can be intentionally tuned. It is known that the oxidation reaction of imines was initiated by their fragmentating into aldehydes and amines via hydrolysis ${ }^{32,44}$. And the activity for hydrolysis reaction over manganese oxide catalysts is closely related to the Lewis acidity on the catalyst surface ${ }^{30,45}$. Most likely, the change of Lewis acid sites availability via acac modification on the surface of $\mathrm{MnO}_{\mathrm{x}}$ catalysts should directly influence the reactivity of imines. To test this hypothesis, we subsequently examined the effect of 

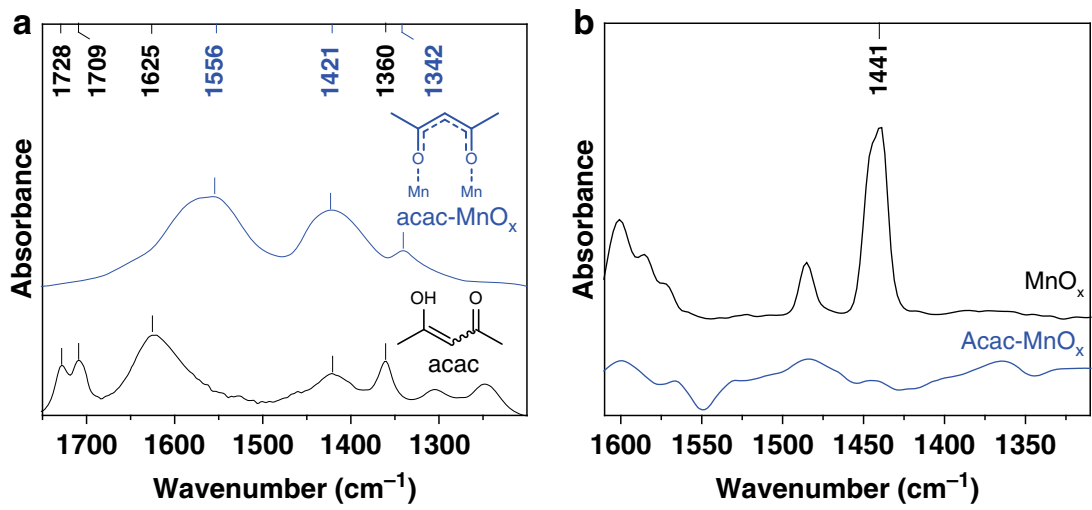

Fig. 2 Catalyst characterization. a FT-IR spectra of acac and acac- $\mathrm{MnO}_{x}$ after evacuation at $150^{\circ} \mathrm{C}$ for $0.5 \mathrm{~h}$. $\mathbf{b}$ FT-IR spectra of pyridine adsorption to $\mathrm{MnO} \mathrm{X}_{\mathrm{x}}$ and acac- $\mathrm{MnO}_{x}$
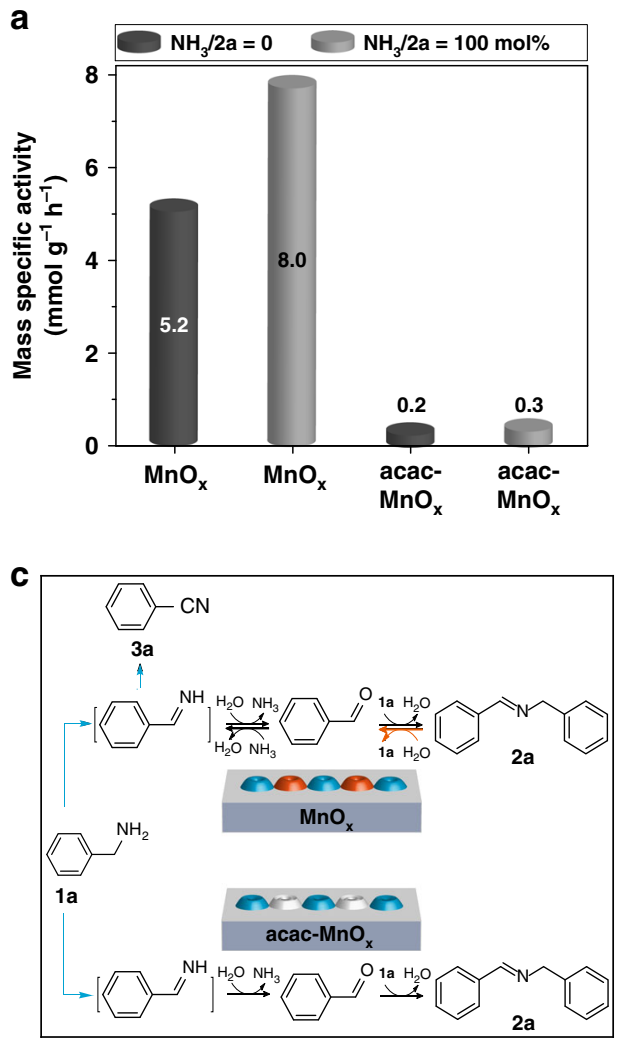

b

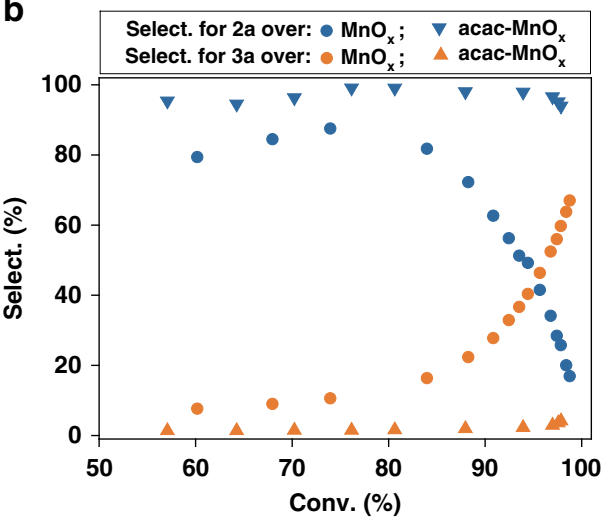

d

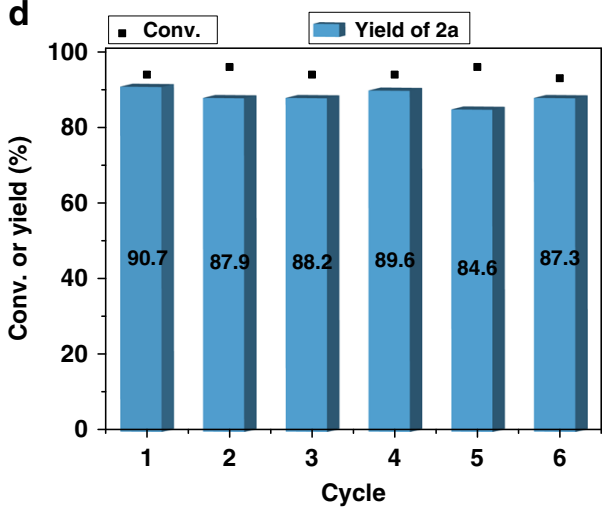

Fig. 3 Reactivity of $N$-benzylidenebenzylamine (2a) over unmodified and acac-modified $\mathrm{MnO}_{\mathrm{x}}$. a Mass-specific activities ( $\mathrm{mmol}_{\text {cat }}{ }^{-1} \mathrm{~h}^{-1}$ ) of $\mathrm{MnO}_{\mathrm{x}}$ and acac- $\mathrm{MnO}_{x}$ in aerobic oxidation/ammoxidation of $\mathrm{N}$-benzylidenebenzylamine (2a) under $0.3 \mathrm{MPa}_{2}$ at $90^{\circ} \mathrm{C}$. The mass-specific activity was measured at the reaction time of $1 \mathrm{~h}$ when the conversion is below $30 \%$. b Selectivity-conversion correlation of $\mathrm{N}$-benzylidenebenzylamine (2a) in aerobic oxidation of benzylamine under $0.3 \mathrm{MPa} \mathrm{O}_{2}$ at $90^{\circ} \mathrm{C}$. c Proposed mechanism. d Recyclability test results for selective synthesis of $\mathrm{N}$-benzylidenebenzylamine (2a) by oxidation of benzylamine over acac modified $\mathrm{MnO}_{\mathrm{x}}$. Reaction conditions: $1 \mathrm{mmol}$ benzylamine, $0.1 \mathrm{mmol} \mathrm{MnO}_{\mathrm{x}}, \mathrm{acac} / \mathrm{MnO}_{\mathrm{x}}=20 \mathrm{~mol} \%, 5 \mathrm{~mL} \mathrm{CH} 3 \mathrm{CN}$, $0.3 \mathrm{MPaO} \mathrm{O}_{2}, 90^{\circ} \mathrm{C}, 14 \mathrm{~h}$

acac surface modification on the oxidative reactivity of imine (Fig. 3a). Unmodified $\mathrm{MnO}_{\mathrm{x}}$ showed obvious activity based on the $2 \mathrm{a}$ conversion $\left(5 \mathrm{mmol} \mathrm{g}_{\mathrm{cat}}{ }^{-1} \mathrm{~h}^{-1}\right.$ for aerobic oxidation, 8 $\mathrm{mmol} \mathrm{g}_{\mathrm{cat}}{ }^{-1} \mathrm{~h}^{-1}$ for aerobic ammoxidation). Notably, the acacmodified catalysts exhibited a distinct decrease in activities for both 2a oxidation and ammoxidation. Consequently, the $\mathrm{MnO}_{\mathrm{x}}$ with inhibited acid properties via acac modification contributed to the extinguished reactivity of imine.
To obtain a better understanding of the role of acac modification in the primary amine oxidation reaction catalyzed by $\mathrm{MnO}_{\mathrm{x}}$, we analyzed the catalytic selectivity in the aerobic oxidation of benzylamine over a broad range of conversions (Fig. 3b). It is widely accepted that the oxidation of benzylamine initially generates aldimine as the intermediate product, which can be hydrolyzed or directly oxidized according to the redox or coordinative properties of catalysts ${ }^{11}$. Herein, unmodified $\mathrm{MnO}_{\mathrm{x}}$ 
gave $2 \mathbf{a}$ in the selectivity of around $80 \%$ at the conversion below $80 \%$. Concomitantly, a steadily increased selectivity for $\mathbf{3 a}$ was observed with increasing the conversion. This indicated that hydrolysis of aldimine occurred as the main reaction to give aldehyde instead of the direct oxidation to generate 3a. And the imine of $\mathbf{2 a}$ should be formed via the facile condensation reaction of benzaldehyde with benzylamine. Meanwhile, in situ formed 2a was hydrolyzed back to form aldimine, followed by oxidation to 3a. Remarkably, at the conversion higher than $80 \%$, the selectivity for $\mathbf{2 a}$ rapidly decreased, accompanied by a significant increase in the selectivity for $\mathbf{3 a}$, rationalizing the reaction pathway shown in Fig. 3c. This indicated that the reversibility of the condensation reaction step between benzaldehyde and benzylamine directly influenced the resultant selectivity. By contrast, 3a was scarcely formed over acac-modified $\mathrm{MnO}_{\mathrm{x}}$ at the conversions ranging from 50 to $98 \%$, and the selectivity for $\mathbf{2 a}$ is $>90 \%$, indicating a highly favorable active-site selection effect of acac modifiers. Thus, after inhibition of the reactivity of imine, acac modified $\mathrm{MnO}_{\mathrm{x}}$ catalyst exhibited only specific types of sites required for aerobic dehydrogenation-coupling of benzylamine (1a) to form imine.

One of the central issues challenging the continued development and refinement of this surface modification technique concerns the stability of the organic modification under demanding reaction conditions. In order to examine the catalytic performance over extended periods of time, we attempted to recycle the catalyst without regeneration. As shown in Fig. $3 \mathrm{~d}$, the catalyst can be recycled for at least 5 times to give a TON of 57 without selectivity loss, suggesting that the regulated surface properties of acac-modified catalyst are not destroyed under the reaction conditions. This should be ascribed to the ability of acac to form stable coordination complexes on the surface of $\mathrm{MnO}_{\mathrm{x}}$.

Synthesis of nitriles and imines. Figure 4 shows data for aerobic oxidation of various substituted benzylamines (see Supplementary Table 2 and Supplementary Figs. 9-38 for detailed data) on $\mathrm{MnO}_{\mathrm{x}}$ and acac- $\mathrm{MnO}_{\mathrm{x}}$ catalysts, respectively. The $\mathrm{MnO}_{\mathrm{x}}$ catalyst is generally active and selective for the nitriles, while the acac$\mathrm{MnO}_{\mathrm{x}}$ catalyst is highly selective for the imines. In the presence of

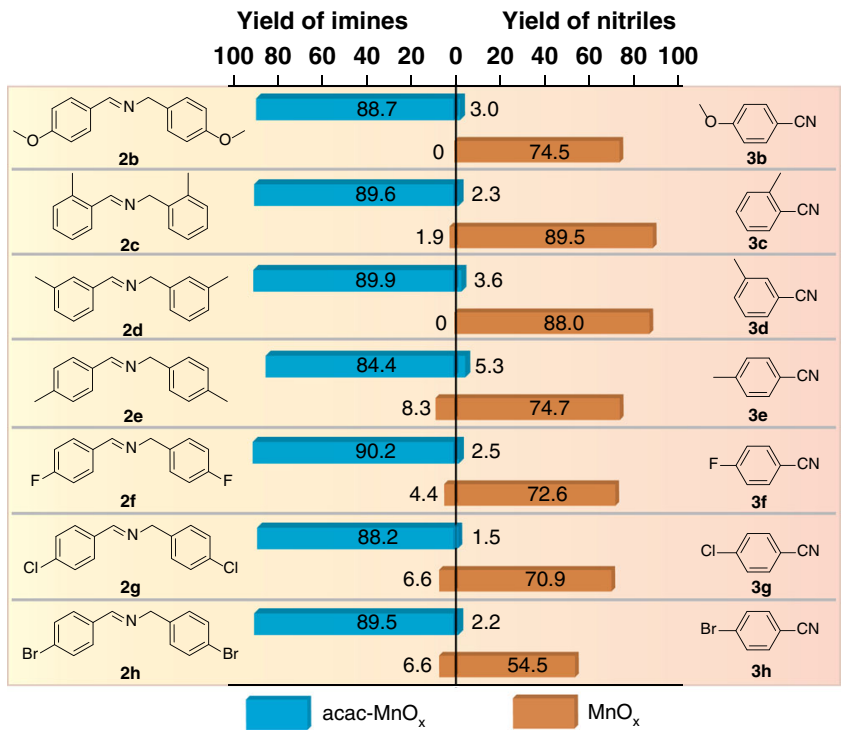

Fig. 4 Synthesis of nitriles and imines using benzylamine derivatives over unmodified and acac-modified $\mathrm{MnO}_{\mathrm{x}}$. Reaction conditions: $1 \mathrm{mmol}$ benzylamine, $0.1 \mathrm{mmol} \mathrm{MnO}_{\mathrm{x}}$, acac $/ \mathrm{MnO}_{\mathrm{x}}=20 \mathrm{~mol} \%$ for acac $-\mathrm{MnO}_{\mathrm{x}}$ $5 \mathrm{~mL} \mathrm{CH}{ }_{3} \mathrm{CN}, 0.3 \mathrm{MPa} \mathrm{O}_{2}, 90^{\circ} \mathrm{C}, 14 \mathrm{~h}$
$\mathrm{MnO}_{\mathrm{x}}$ catalyst, benzylamine derivatives bearing electrondonating groups gave the corresponding nitriles in relative higher yields in comparison with those bearing electronwithdrawing groups, due to the facile hydrolysis reaction of electron-withdrawing groups substituted nitriles to amides. For acac- $\mathrm{MnO}_{\mathrm{x}}$ catalyst, benzylamine derivatives bearing both electron-donating and electron-withdrawing groups reacted to produce the corresponding imines in good to excellent conversions and yields.

\section{Discussion}

In summary, we have demonstrated a method of using organic modifiers to tune the reaction pathway of redox-acid catalysis on the surface of metal oxide catalysts. Upon modification with enolic acetylacetones, the selectivity for manganese oxide catalyzed primary amines oxidation reaction switched from nitriles to imines. The acetylacetone modification is stable under the reaction conditions and demonstrated good recyclability. The current study opens the door to the development of a class of highly stable and selectivity-switchable metal oxide catalysts via using the versatility of organic ligands to tune the surface properties of metal oxide catalysts.

\section{Methods}

Preparation of $\mathbf{M n O}_{\mathbf{x}} \cdot \mathrm{MnO}_{\mathbf{x}}$ was prepared according to the literature procedure ${ }^{23}$ A $100 \mathrm{~mL}$ aqueous solution containing $40 \mathrm{mmol} \mathrm{KMnO}_{4}$ was added into another $250 \mathrm{~mL}$ solution of EtOH- $\mathrm{H}_{2} \mathrm{O}$ (5:1) containing $40 \mathrm{mmol} \mathrm{MnAc}_{2}$. After addition complete, adjust the $\mathrm{pH}$ to 8 with aq. $\mathrm{NH}_{3}$, then the mixture was stirred at room temperature for $12 \mathrm{~h}$, the resulting solid was collected by filtration, washed repeatedly with distilled water, and finally dried for $48 \mathrm{~h}$ in air at $80^{\circ} \mathrm{C}$.

Preparation of organic modified $\mathbf{M n O}_{\mathbf{x}}$. Surface organic modified catalysts were prepared by immersing the catalyst in an acetonitrile solution of modifiers. After stirring at $90^{\circ} \mathrm{C}$ for $4 \mathrm{~h}$, the mixture of modifier solution and the catalyst was used for reaction without further separation.

Catalyst characterization. In situ FT-IR spectra of the acac- $\mathrm{MnO}_{\mathrm{x}}$ and pyridine adspecies on the catalysts were recorded with a TENSOR 27 spectrometer equipped with an in situ IR cell connected to a conventional gas flow system. The samples (20-30 mg) were pressed into self-supporting wafers (20 $\mathrm{mm}$ in diameter) and mounted in the IR cell. The adsorption of acetylacetone on $\mathrm{MnO}_{\mathrm{x}}$ was characterized with the following method: The acac- $\mathrm{MnO}_{\mathrm{x}}$ sample was pretreated at 150 ${ }^{\circ} \mathrm{C}$ under vacuum $\left(<10^{-1} \mathrm{~Pa}\right)$ for $30 \mathrm{~min}$. After cooling to $30^{\circ} \mathrm{C}$, IR measurements were carried out. The adsorption of pyridine was carried out with the following method: The sample was pretreated at $150^{\circ} \mathrm{C}$ under vacuum $\left(<10^{-1} \mathrm{~Pa}\right)$ for 30 min. After cooling to $30^{\circ} \mathrm{C}$, pyridine was fed into the in situ IR cell under vacuum $\left(<10^{-1} \mathrm{~Pa}\right)$. Then, the sample was heated at $150^{\circ} \mathrm{C}$ for $30 \mathrm{~min}$ to remove the physical adsorbed pyridine. And IR measurements were carried out after cooling to $30^{\circ} \mathrm{C}$.

General experimental procedures. Catalytic reactions were performed in a $20 \mathrm{~mL}$ stainless-steel autoclave equipped with a magnetic stirrer, a pressure gauge, and automatic temperature control apparatus. The reactor was connected to an oxygen cylinder for reaction pressure. In a typical experiment, benzylamine $(107.5 \mathrm{mg}, 1$ $\mathrm{mmol}$ ) and the prepared suspension of organic modified $\mathrm{MnO}_{\mathrm{x}}$ were loaded into the reactor. After sealing and charging with $\mathrm{O}_{2}(0.3 \mathrm{MPa})$, the autoclave was heated to the desired temperature $\left(90^{\circ} \mathrm{C}\right)$. After reaction, the autoclave was cooled. The solution was separated by centrifugation and analyzed by GC using the internal standard method. The error bars (standard deviation) were calculated from repeat measurements.

The products were identified by Agilent $6890 \mathrm{~N} \mathrm{GC/5973MS}$ as well as by comparison with the retention times to corresponding standards in GC traces. Gas chromatography measurements were conducted on Agilent 7890 A GC with autosampler and a flame ionization detector. DB-17 capillary column $(30 \mathrm{~m} \times 320$ $\mu \mathrm{m} \times 0.25 \mu \mathrm{m}$ ) was used for separation of reaction mixtures. The temperature of the column was kept at $100^{\circ} \mathrm{C}$ for $3 \mathrm{~min}$, then increased to $280^{\circ} \mathrm{C}$ at a rate of $15^{\circ} \mathrm{C}$ $\min ^{-1}$ and kept for $6 \mathrm{~min}$. The conversion of benzylamine and yield of corresponding products were evaluated using naphthalene as the internal standard. The conversion of other substrates and yield of corresponding products were determined based on area normalization without any purification. 


\section{Data availability}

All data generated and analyzed during this study are included in this Article and its Supplementary Information or are available from the corresponding author upon reasonable request.

Received: 20 December 2018 Accepted: 1 May 2019

Published online: 28 May 2019

\section{References}

1. Corma, A. \& Serna, P. Chemoselective hydrogenation of nitro compounds with supported gold catalysts. Science 313, 332-334 (2006).

2. Marshall, S. T. et al. Controlled selectivity for palladium catalysts using selfassembled monolayers. Nat. Mater. 9, 853-858 (2010).

3. Chen, G. et al. Interfacial electronic effects control the reaction selectivity of platinum catalysts. Nat. Mater. 15, 564-569 (2016).

4. Matsubu, J. C. et al. Adsorbate-mediated strong metal-support interactions in oxide-supported Rh catalysts. Nat. Chem. 9, 120-127 (2017).

5. Tan, Y. et al. ZnAl-hydrotalcite-supported $\mathrm{Au}_{25}$ nanoclusters as precatalysts for chemoselective hydrogenation of 3-nitrostyrene. Angew. Chem. Int. Ed. 56, 2709-2713 (2017).

6. $\mathrm{Xu}, \mathrm{B}$. et al. Simple copper catalysts for the aerobic oxidation of amines: selectivity control by the counterion. Angew. Chem. Int. Ed. 55, 15802-15806 (2016).

7. Li, S., Zhu, S., Zhang, C., Song, S. \& Zhou, Q. Iridium-catalyzed enantioselective hydrogenation of $\alpha, \beta$-unsaturated carboxylic acids. J. Am. Chem. Soc. 130, 8584-8585 (2008).

8. Schoenbaum, C. A., Schwartz, D. K. \& Medlin, J. W. Controlling the surface environment of heterogeneous catalysts using self-assembled monolayers. Acc. Chem. Res. 47, 1438-1445 (2014).

9. Tian, S. et al. Temperature-controlled selectivity of hydrogenation and hydrodeoxygenation in the conversion of biomass molecule by the $\mathrm{Ru}_{1} / \mathrm{mpg}$ $\mathrm{C}_{3} \mathrm{~N}_{4}$ catalyst. J. Am. Chem. Soc. 140, 11161-11164 (2018).

10. Li, S. et al. Tuning the selectivity of catalytic carbon dioxide hydrogenation over iridium/cerium oxide catalysts with a strong metal-support interaction. Angew. Chem. Int. Ed. 56, 10761-10765 (2017)

11. Schümperli, M. T., Hammond, C. \& Hermans, I. Developments in the aerobic oxidation of amines. ACS Catal. 2, 1108-1117 (2012).

12. Wang, L. et al. Controllable cyanation of carbon-hydrogen bonds by zeolite crystals over manganese oxide catalyst. Nat. Commun. 8, 15240 (2017).

13. Zhang, J., Wang, B., Nikolla, E. \& Medlin, J. W. Directing reaction pathways through controlled reactant binding at $\mathrm{Pd}-\mathrm{TiO}_{2}$ interfaces. Angew. Chem. Int. Ed. 56, 6594-6598 (2017).

14. Zhang, J. et al. A Pd@zeolite catalyst for nitroarene hydrogenation with high product selectivity by sterically controlled adsorption in the zeolite micropores. Angew. Chem. Int. Ed. 56, 9747-9751 (2017).

15. Liu, P., Qin, R., Fu, G. \& Zheng, N. Surface coordination chemistry of metal nanomaterials. J. Am. Chem. Soc. 139, 2122-2131 (2017)

16. Schrader, I., Warneke, J., Backenkoehler, J. \& Kunz, S. Functionalization of platinum nanoparticles with L-proline: simultaneous enhancements of catalytic activity and selectivity. J. Am. Chem. Soc. 137, 905-912 (2015).

17. Wu, B., Huang, H., Yang, J., Zheng, N. \& Fu, G. Selective hydrogenation of alpha, beta-unsaturated aldehydes catalyzed by amine-capped platinum-cobalt nanocrystals. Angew. Chem. Int. Ed. 51, 3440-3443 (2012).

18. Pang, S. H., Schoenbaum, C. A., Schwartz, D. K. \& Medlin, J. W. Directing reaction pathways by catalyst active-site selection using self-assembled monolayers. Nat. Commun. 4, 2448 (2013).

19. Kahsar, K. R., Schwartz, D. K. \& Medlin, J. W. Control of metal catalyst selectivity through specific noncovalent molecular interactions. J. Am. Chem. Soc. 136, 520-526 (2014)

20. Ernst, J. B., Muratsugu, S., Wang, F., Tada, M. \& Glorius, F. Tunable heterogeneous catalysis: $\mathrm{N}$-heterocyclic carbenes as ligands for supported heterogeneous $\mathrm{Ru} / \mathrm{K}-\mathrm{Al}_{2} \mathrm{O}_{3}$ catalysts to tune reactivity and selectivity. J. Am. Chem. Soc. 138, 10718-10721 (2016).

21. Zhang, J. et al. Control of interfacial acid-metal catalysis with organic monolayers. Nat. Catal. 1, 148-155 (2018).

22. Ellis, L. D., Trottier, R. M., Musgrave, C. B., Schwartz, D. K. \& Medlin, J. W. Controlling the surface reactivity of titania via electronic tuning of selfassembled monolayers. ACS Catal. 7, 8351-8357 (2017).

23. Jia, X. et al. Carboxylic acid-modified metal oxide catalyst for selectivitytunable aerobic ammoxidation. Nat. Commun. 9, 933 (2018).

24. Tamura, M. \& Tomishige, K. Redox properties of $\mathrm{CeO}_{2}$ at low temperature: the direct synthesis of imines from alcohol and amine. Angew. Chem. Int. Ed. 54, 864-867 (2015).

25. Tamura, M. et al. Formation of a new, strongly basic nitrogen anion by metal oxide modification. J. Am. Chem. Soc. 139, 11857-11867 (2017).
26. Yamaguchi, K., Kobayashi, H., Oishi, T. \& Mizuno, N. Heterogeneously catalyzed synthesis of primary amides directly from primary alcohols and aqueous ammonia. Angew. Chem. Int. Ed. 51, 544-547 (2012).

27. Wang, Y. et al. Heterogeneous ceria catalyst with water-tolerant Lewis acidic sites for one-pot synthesis of 1,3-diols via Prins condensation and hydrolysis reactions. J. Am. Chem. Soc. 135, 1506-1515 (2013).

28. Al-Hmoud, L. \& Jones, C. W. Reaction pathways over copper and cerium oxide catalysts for direct synthesis of imines from amines under aerobic conditions. J. Catal. 301, 116-124 (2013).

29. Wang, Y., Kobayashi, H., Yamaguchi, K. \& Mizuno, N. Manganese oxidecatalyzed transformation of primary amines to primary amides through the sequence of oxidative dehydrogenation and successive hydration. Chem. Commun. 48, 2642-2644 (2012).

30. Yamaguchi, K., Wang, Y. \& Mizuno, N. Manganese oxide-catalyzed additiveand solvent-free aerobic oxidative synthesis of primary amides from primary amines. Chem. Lett. 41, 633-635 (2012).

31. Biswas, S. et al. Aerobic oxidation of amines to imines by cesium-promoted mesoporous manganese oxide. ACS Catal. 5, 4394-4403 (2015).

32. Sudarsanam, P., Hillary, B., Amin, M. H., Hamid, S. B. A. \& Bhargava, S. K. Structure-activity relationships of nanoscale $\mathrm{MnO}_{\mathrm{x}} / \mathrm{CeO}_{2}$ heterostructured catalysts for selective oxidation of amines under eco-friendly conditions. Appl. Catal. B Environ. 185, 213-224 (2016).

33. McNamara, W. R. et al. Acetylacetonate anchors for robust functionalization of $\mathrm{TiO}_{2}$ nanoparticles with $\mathrm{Mn}(\mathrm{II})$-terpyridine complexes. J. Am. Chem. Soc. 130, 14329-14338 (2008).

34. Xiao, D., Martini, L. A., Snoeberger, R. C. 3rd, Crabtree, R. H. \& Batista, V. S. Inverse design and synthesis of acac-coumarin anchors for robust $\mathrm{TiO}_{2}$ sensitization. J. Am. Chem. Soc. 133, 9014-9022 (2011).

35. Le Bahers, T., Pauporte, T., Labat, F., Lefevre, G. \& Ciofini, I. Acetylacetone, an interesting anchoring group for $\mathrm{ZnO}$-based organic-inorganic hybrid materials: a combined experimental and theoretical study. Langmuir 27, 3442-3450 (2011).

36. Burdett, J. L. \& Rogers, M. T. Keto-enol tautomerism in $\beta$-dicarbonyls studied by nuclear magnetic resonance spectroscopy. I. Proton chemical shifts and equilibrium constants of pure compounds. J. Am. Chem. Soc. 86, 2105-2109 (1964).

37. Caminati, W. \& Grabow, J. U. The $\mathrm{C}_{2 \mathrm{v}}$ structure of enolic acetylacetone. J. Am Chem. Soc. 128, 854-857 (2006).

38. McCann, B. W., McFarland, S. \& Acevedo, O. Benchmarking continuum solvent models for keto-enol tautomerizations. J. Phys. Chem. A 119, 8724-8733 (2015).

39. Rogan, J. B. \& Ellis, D. J. Conformations of 3,3-dimethyl-2,4-pentanedione. J. Org. Chem. 26, 5232-5233 (1961).

40. Trivella, A. et al. UV and IR photoisomerization of acetylacetone trapped in a nitrogen matrix. J. Phys. Chem. A 111, 3074-3081 (2007).

41. Pinchas, S., Silver, B. L. \& Laulicht, I. Infrared absorption spectra of the ${ }^{18} \mathrm{O}$ labeled acetylacetonates of $\mathrm{Cr}(\mathrm{III})$ and $\mathrm{Mn}(\mathrm{III})$. J. Chem. Phys. 46, 1506-1510 (1967).

42. Saberi, D., Mahdudi, S., Cheraghi, S. \& Heydari, A. Cu(II)-acetylacetone complex covalently anchored onto magnetic nanoparticles: synthesis, characterization and catalytic evaluation in amide bond formation via oxidative coupling of carboxylic acids with $\mathrm{N}, \mathrm{N}$-dialkylformamides. J. Organomet. Chem. 772-773, 222-228 (2014).

43. Li, J., Wang, R. \& Hao, J. Role of lattice oxygen and Lewis acid on ethanol oxidation over OMS-2 catalyst. J. Phys. Chem. C 114, 10544-10550 (2010).

44. Furukawa, S., Suga, A. \& Komatsu, T. Mechanistic study on aerobic oxidation of amine over intermetallic $\mathrm{Pd}_{3} \mathrm{~Pb}$ : concerted promotion effects by $\mathrm{Pb}$ and support basicity. ACS Catal. 5, 1214-1222 (2015)

45. Yamaguchi, K. et al. Green oxidative synthesis of primary amides from primary alcohols or aldehydes catalyzed by a cryptomelane-type manganese oxide-based octahedral molecular sieve, OMS-2. Catal. Sci. Technol. 3, 318-327 (2013)

\section{Acknowledgements}

This work was supported by the National Natural Science Foundation of China (projects 21703236 and 21790331), the Strategic Priority Research Program of the Chinese Academy of Sciences (No. XDB17020300 and XDA21030400), the Youth Innovation Promotion Association, the Chinese Academy of Sciences (2018219) and DICP ZZBS201811. This paper is dedicated to the 70th anniversary of the Dalian Institute of Chemical Physics, Chinese Academy of Sciences.

\section{Author contributions}

X.J. designed the project and performed the catalyst preparation, characterizations, and tests and completed the paper. F.X, M.G., and J.G. participated in beneficial discussions. J.M. and J.X. proposed, planned, designed, and supervised the project. All authors reviewed and commented on the manuscript. 


\section{Additional information}

Supplementary Information accompanies this paper at https://doi.org/10.1038/s41467019-10315-9.

Competing interests: The authors declare no competing interests.

Reprints and permission information is available online at http://npg.nature.com/ reprintsandpermissions/

Journal peer review information: Nature Communications thanks the anonymous reviewers for their contribution to the peer review of this work. Peer reviewer reports are available.

Publisher's note: Springer Nature remains neutral with regard to jurisdictional claims in published maps and institutional affiliations. (c) (i) Open Access This article is licensed under a Creative Commons Attribution 4.0 International License, which permits use, sharing, adaptation, distribution and reproduction in any medium or format, as long as you give appropriate credit to the original author(s) and the source, provide a link to the Creative Commons license, and indicate if changes were made. The images or other third party material in this article are included in the article's Creative Commons license, unless indicated otherwise in a credit line to the material. If material is not included in the article's Creative Commons license and your intended use is not permitted by statutory regulation or exceeds the permitted use, you will need to obtain permission directly from the copyright holder. To view a copy of this license, visit http://creativecommons.org/ licenses/by/4.0/.

(C) The Author(s) 2019 